\title{
ACTIVIDAD ANTIMICROBIANA DE LA STEVIA EN COMPARACIÓN CON EL XILITOL, FRENTE A LOS STREPTOCOCCUS MUTANS - UN ESTUDIO IN VITRO
}

\section{STEVIA ANTIMICROBIAL ACTIVITY COMPARED TO XYLITOL, AGAINST STREPTOCOCCUS MUTANS - A STUDY IN VITRO}

\author{
Tovar-Huaynate Gina. ${ }^{1 *}$, Cupé-Araujo Ana Cecilia.${ }^{1, a}$ \\ ${ }^{1}$ Universidad Privada Norbert Wiener. Perú. \\ a Especialista en Odontopediatría, Magíster en Estomatología con mención en Odontología Pediátrica. Perú. \\ *aries_angely_21@hotmail.com
}

\begin{abstract}
Resumen
OBJETIVO: El objetivo de este estudio fue demostrar la actividad antimicrobiana de la Stevia en comparación con el Xilitol, frente a los Streptococcus mutans.MATERIALES Y MÉTODOS: Este estudio fue de carácter experimental; se llevó al laboratorio microbiológico cepas de Streptococcus mutans (ATCC 25175) y se hizo el cultivo sobre Agar Mueller Hinton (OXOID) con sangre de cordero desfibrinada y se comparó el efecto antimicrobiano de la Stevia y el Xilitol utilizando la técnica de Agar difusión con bacterias y perforación en placa ,como control positivo se utilizó clorhexidina al $2 \%$ (MAQUIRA) y el control negativo el agua ;se colocaron en campanas de incubación a 37 grados Centigrados y se evaluaron a las 24, 48 horas después para determinar el efecto de estos extractos sobre el crecimiento de las bacterias.RESULTADOS: Se determinó la alta inhibición de la actividad microbiana de Stevia frente a los Streptococcus mutans en comparación al Xilitol con dilución. En el estudio se observó mayor crecimiento de los halos de inhibición. CONCLUSIÓN: La Stevia tiene mayor actividad antimicrobiana que el xilitol ya que en ambos controles se observó formación de halos de mayor tamaño demostrando el potencial anticariogénico de este endulzante natural. Este estudio fue de tipo Prospectivo - Longitudinal Experimental - Analítico.
\end{abstract}

Palabras clave: Stevia, xilitol, edulcorantes, Streptococcus mutans.

\begin{abstract}
AIM: The objective of this study was to demonstrate the antimicrobial activity of Stevia compared to Xylitol against the Streptococci mutans. This was an experimental trial.MATERIALS AND METHODS: Was made by taking the strains of Streptococcus mutans to the microbiology laboratory (ATCC 25175) and grown on Agar Mueller Hinton (OXOID) with defibrinated sheep blood. The antimicrobial effect of Stevia and Xylitol were compared using the technique of Agar diffusion bacteria and drilling plate as a positive control $2 \%$ of chlorhexidine (Maquira) and negative water control were used. It was placed in bells incubation at 37 degrees Celsius and evaluated at 24, 48 hours to determine the effect of these extracts on growth of bacteria.RESULTS: high inhibition of microbial activity of Stevia was determined against Streptococcus mutans compared to Xylitol dilution. In the trial a greater growth inhibition halos was observed. CONCLUSION: Stevia has greater antimicrobial activity than xylitol since both controls larger halos were observed demonstrating the potential of this anticariogenic natural sweetener. This study was prospective - Longitudinal - Experimental - Analytical
\end{abstract}

Key words: Stevia, xylitol, sweeteners, Streptococcus mutans.

\section{INTRODUCCIÓN}

Los Streptococcus mutans son bacterias relacionadas directamente con el inicio de la caries dental debido a su potencial cariogénico. ${ }^{1}$ La homeostasis microbiana oral es "la capacidad de mantener la estabilidad de la comunidad en un ambiente variable" cuando existe un cambio en este equilibrio en el que se encuentra la microbiota oral debido a una alteración en los entornos ambientales locales, como consecuencia se origina la caries dental de acuerdo a la hipótesis ecológica de la placa. ${ }^{2}$ Streptococcus mutans por 
sus propiedades acidúricas y acidogénicas puede fermentar los carbohidratos como la sacarosa, glucosa, fructosa y producir ácido láctico, ácido propiónico, ácido acético y ácido fórmico. Estos ácidos circulan a través del biofilm dental y reaccionan con la superficie porosa del esmalte, disociándose y liberando iones de hidrógeno, éstos pueden disolver ágilmente el mineral del esmalte, cediendo iones calcio y fosfato, de esta manera se descompone la estructura de la hidroxiapatita del esmalte. Este proceso se conoce como desmineralización. ${ }^{3}$ La Stevia principalmente es usada en el tratamiento de alteraciones de la piel, sustituto del azúcar y en prevención de caries. Se ha informado que tiene efectos bactericidas sobre Streptococcus mutans, al poseer propiedades antibacterianas y antivirales. ${ }^{4}$ Los esteviósidos regulan el nivel de glucosa en la sangre debido al aumento en la producción de insulina y una mejor utilización de la glucosa por los tejidos periféricos y los músculos en ratas diabéticas; a su vez se postula que los esteviósidos neutralizan la glucotoxicidad en la células beta o también suprimé la excreción de glucagón por parte de las células alfa del páncreas. ${ }^{5}$

La Stevia no contiene calorías y las hojas de la planta pueden utilizarse en su estado natural en pequeñas cantidades, a causa de su gran poder edulcorante. ${ }^{6}$ El Xilitol remineraliza el diente y el hueso, es antimicótica y antibacteriano principalmente sobre Streptococcus mutans en la saliva además de mejorar el flujo salival, biofilm dental, mejora la flora bacteriana y el sistema inmunológico. Con propiedades demostradas en varios estudios se puede decir que el Xilitol inhibe el crecimiento del microorganismo causante de caries dental Streptococcus mutans, debido al efecto del Xilitol sobre el metabolismo bacteriano lo que reduce el índice de crecimiento y la producción de ácido por parte de la bacteria. Con el uso del Xilitol, a través del tiempo con lleva a niveles reducidos de la bacteria cariogénica en la boca y por ende menos caries sobre las superficies de los dientes. Se forma menos Biofilm dental y reduce la producción de ácidos que atacan las superficies de los dientes, bloqueando de esta manera la alteración de las características del esmalte y estimulando la remineralización. ${ }^{1,7}$

\section{MATERIALES Y MÉTODOS}

Se realizó una investigación de carácter experimental en donde a través de un estudio in vitro se comparó la influencia de la Stevia y el Xilitol sobre el crecimiento de cepas de Streptococcus mutans (ATCC 25175). Para la obtención del extracto se diluyó 100 gr de Xilitol en azúcar en $100 \mathrm{~mL}$ de agua destilada utilizado como solvente (dilución al $100 \%$ ) posteriormente se colocó en frascos estériles; se compró el extracto de Stevia de la marca NUTRASTEVIA y clorhexidina al $2 \%$ (MAQUIRA). Una vez obtenidas las diluciones a la concentración deseada, se preparó el medio de cultivo utilizando Agar Mueller Hinton (OXOID) con sangre de cordero desfibrinada, para 8 frascos de $500 \mathrm{ml}$ se colocó 150 gr de Agar Mueller Hinton posteriormente se procedió a llevar al autoclave a 121 grados centigrados por 15 minutos. El ensayo microbiológico se realizó con técnica de agar difusión con bacterias y perforación en placa; se preparó una suspensión en caldo nutritivo de la bacteria, una vez que el agar tomó la temperatura deseada (aún en estado líquido), se combina con la sangre de cordero y se colocó $80 \mathrm{~mL}$ de la suspensión con una probeta y fueron suspendidas en las 25 placas Petri.

Cuando el agar gelificó, se procedió a hacer cuatro pozos en cada placa Petri con medida de $6 \mathrm{~mm}$ de diámetro, se realizó la siembra de la suspensión en caldo nutritivo de Streptococcus mutans con hisopos estériles por toda la superficie del Agar; se aplicó con una micropipeta $40 \mathrm{uL}$ de las diluciones de cada extracto y de las soluciones de control en los pozos; el ensayo se realizó de forma duplicada con cada uno de los extractos. Las cajas de Petri se taparon y se dejaron reposar a temperatura ambiente durante 30 minutos para lograr una mejor difusión de la sustancia; luego estas mismas se colocaron dentro de las jarras de anaerobiosis y cerradas con una vela encendida por dentro disminuyendo el oxígeno y así generar producción de $\mathrm{CO} 2$ mediante la combustión incompleta y posteriormente introducirlas en la campana de incubación a 37 grados centigrados y se evaluaron a las 24 , 48 horas después para determinar el efecto de estos extractos en el crecimiento de las bacterias.

\section{RESULTADOS}

Se determinó que la Stevia tiene alta inhibición de la actividad microbiana frente a los Streptococcus mutans en comparación al Xilitol con dilución ya que en la experiencia se observó mayor crecimiento de los halos de inhibición observando una diferencia considerable.

La Stevia tiene alta actividad antimicrobiana frente a los Streptococcus mutans ya que a las 24 horas presentó halos de inhibición bacteriana de $13.2 \mathrm{~mm}$ en promedio y a las 48 horas dichos halos de inhibición bacteriana crecieron hasta llegar a $14.61 \mathrm{~mm}$.

El Xilitol presenta alta actividad antimicrobiana frente a los Streptococcus mutans ya que se observó formación de halos de inhibición bacteriana de $8.6 \mathrm{~mm}$ en promedio a las 24 horas y de $9.51 \mathrm{~mm}$ a las 48 horas de control.

Se determinó que la Stevia y el Xilitol presentan alta actividad antimicrobiana; según las estadísticas a las 24 horas la Stevia presentó halos de inhibición de $13.2 \mathrm{~mm}$ y a las 48 horas presentó halos de $14.61 \mathrm{~mm}$ a diferencia del Xilitol que en su primer control de 24 horas presentó halos de 8.6 mm y a las 48 horas presentó halos de $9.51 \mathrm{~mm}$ demostrando que ambos presentan alta actividad antimicrobiana pero la Stevia tiene mayor actividad antimicrobiana frente a los Streptococcus mutans. 


\section{DISCUSIÓN}

El presente estudio es un trabajo inédito que ha comparado dos edulcorantes como son la Stevia y el Xilitol. Laprade, ${ }^{8}$ realizó un estudio in vitro donde analizó la eficacia del colutorio de Gluconato de Clorhexidina frente los Streptococcus mutans y otras bacterias de la cavidad bucal, determinando que el gluconato de la Clorhexidina no es eficaz frente a los Streptococcus mutans. Este estudio no concuerda con estos resultados ya que se demostró la eficacia y la gran actividad antimicrobiana de la Clorhexidina al $2 \%$ frente a los Streptococcus mutans. Así mismo Velasquez, ${ }^{9}$ evaluó el uso de la goma de mascar con Xilitol asegurando que esta reducía la cantidad del biofilm dental, aumentaba el flujo salival y el $\mathrm{pH}$, en la cual se concuerda con la afirmación de este ya que se pudo demostrar la efectividad del Xilitol frente a los Streptococcus mutans, bacterias que están presentes en la cavidad bucal.

Bahador A et, ${ }^{10}$ al aseguran que el consumo habitual de Xilitol reduce el número de Streptococcus mutans por lo tanto reduce los niveles cariogénicos, este estudio concuerda con el autor ya que se comprobó la eficacia del Xilitol frente a los Streptococcus mutans bacterias más frecuentes de la cavidad bucal causantes de la caries.

Por otro lado Gholam R et al, ${ }^{11}$ estudiaron los efectos del Xilitol y el Eritritol en el crecimiento de los Streptococcus mutans y comparar sus efectos. Independientemente de la concentración se encontró un resultado más eficaz en el Eritritol que en el Xilitol en la inhibición del crecimiento y la formación de biofilm de cepas de Streptococcus utilizados en este estudio. Este estudio concuerda con el autor ya que en el presente estudio también se comparó dos endulzantes (Stevia y Xilitol) en las cuales los resultados microbiológicos fueron similares el Xilitol presentó menor actividad antimicrobiana que la Stevia; en conclusión si reduce la actividad microbiana de los Streptococcus mutans. Vitery G et al, ${ }^{12}$ aseguran que la Stevia tiene actividad antimicrobiana sobre el crecimiento de cepas de Streptococcus mutans, esta teoría se reafirma en este estudio ya que se logró demostrar la actividad antimicrobiana de la Stevia frente a los Streptococcus mutans mostrando tamaños considerables de halos de inhibición.

Pérez C et al, ${ }^{13}$ estudiaron los cambios en los niveles de Streptococcus mutans en saliva después de usar una goma de mascar que contiene Xilitol, aseguran que el Xilitol reduce la cantidad de Streptococcus mutans en la Saliva y este efecto continuó aun habiéndose detenido el consumo de la goma de mascar con Xilitol, este estudio está de acuerdo con esta teoría ya que en el presente estudio se comprobó que el Xilitol disminuye la actividad antimicrobiana frente los Streptococcus mutans.

Manish B et al, ${ }^{14}$ confirma la potencialidad antimicrobiana del extracto de la hoja de Stevia frente a los Streptococcus mutans, esta teoría se reafirmó en este estudio ya que se observó la formación de halo de inhibición de tamaños considerables. El Xilitol reduce la formación del Biofilm dental

\begin{tabular}{ccc}
\hline \multirow{2}{*}{ Tiempo } & \multicolumn{2}{c}{ Eficacia antimicrobiana } \\
& $\begin{array}{c}\text { Media } \\
(\mathrm{mm})\end{array}$ & Desviación Estándar (mm) \\
\hline 24 Horas & 13.20 & 1.59 \\
48 Horas & 14.61 & 1.27 \\
\hline
\end{tabular}

Tabla 1. Determinar el nivel de la actividad antimicrobiana de la Stevia frente a los Streptococcus Mutans In Vitro, a las 24 y 48 horas.

\begin{tabular}{ccc}
\hline Tiempo & \multicolumn{2}{c}{ Eficacia antimicrobiana } \\
& $\begin{array}{c}\text { Media } \\
(\mathrm{mm})\end{array}$ & Desviación Estándar $(\mathrm{mm})$ \\
\hline 24 Horas & 8.68 & 1.09 \\
48 Horas & 9.51 & 0.51 \\
\hline
\end{tabular}

Tabla 2. Determinar el nivel de la actividad antimicrobiana del Xilitol frente a los Streptococcus Mutans In Vitro, a las 24 y 48 horas.

por tanto disminuye la colonización microbiana de los dientes según asegura Batellino. ${ }^{15}$ Se coincide con el autor ya que en la experiencia se demostró la inhibición de la actividad antimicrobiana del Xilitol.

Lopez $\mathrm{N}$ et al. ${ }^{16}$ Afirma que la solución de fluoruro de sodio con la adición de Xilitol redu- cen significativamente el número de Streptococcus mutans; se concuerda con el autor ya que se puedo comprobar la actividad antimicrobiana del Xilitol frente a la sepa de los Streptococcus mutans.

\section{CONCLUSIONES}

En el presente estudio se determinó que la Stevia tiene alta inhibición de la actividad microbiana frente a los Streptococcus mutans en comparación al Xilitol con dilución ya que en la experiencia se observó mayor crecimiento de los

\begin{tabular}{cccc}
\hline & \multicolumn{3}{c}{ Tiempo } \\
\hline Medicación & $\begin{array}{c}\text { Media } \\
\text { 24m.) }\end{array}$ & $\begin{array}{c}\text { n.S. } \\
(\mathbf{m m} .)\end{array}$ & $\begin{array}{c}\text { Media } \\
(\mathbf{m m} .)\end{array}$ \\
Clorhexidina 2\% & 25.86 & 1.60 & 33.40 \\
Xilitol & 8.68 & 1.09 & 9.51 \\
Stevia & 13.20 & 1.59 & 14.61 \\
\hline
\end{tabular}

Tabla 3. Comparar el nivel de la actividad antimicrobiana de la Stevia, Xilitol y clorhexidina $2 \%$ frente a los Estreptococcus Mutans In Vitro, a las 24 y 48 horas 
halos de inhibición observando una diferencia considerable.

La Stevia tiene alta actividad antimicrobiana frente a los Streptococcus mutans ya que a las 24 horas presentó halos de inhibición bacteriana de $13.2 \mathrm{~mm}$ en promedio y a las 48 horas dichos halos de inhibición bacteriana crecieron hasta llegar a $14.61 \mathrm{~mm}$. halos de inhibición bacteriana de $8.6 \mathrm{~mm}$ en promedio a las 24 horas y de $9.51 \mathrm{~mm}$ a las 48 horas de 14 control.

Se determinó que la Stevia y el Xilitol presentan alta actividad antimicrobiana; según las estadísticas a las 24 horas la Stevia presentó halos de inhibición de $13.2 \mathrm{~mm}$ y a las 48 horas presentó halos de $14.61 \mathrm{~mm}$ a diferencia del Xilitol que en su primer control de 24 horas presentó halos de 8.6 mm y a las 48 horas presentó halos de $9.51 \mathrm{~mm}$ demostrando que ambos presentan alta actividad antimicrobiana pero la Stevia tiene mayor actividad antimicrobiana frente a los Streptococcus mutans.

\section{Referencias}

1 Ojeda-Garcés JC, Oviedo-García E, Salas LA. Streptococcus mutans y caries dental. Rev. CES Odont. 2013; 26(1):44-56.

2 Marsh P. Martin M. Lewis M. Placa Dental. Microbiología Oral. Quinta Edición: Venezuela; 2011. p 74-102.

3 Fátima RS. Algunas consideraciones sobre caries dental, fluoruros, su metabolismo y mecanismos de acción. Acta Odontológica Venezolana. 2008;46(4):1-11.

4 Durán S. y cols. Estevia (stevia rebaudiana), edulcorante natural y no calórico. Rev Chil Nutr.2012;39(4):203-206.

5 Durans S. Estevia (Stevia rebaudiana), edulcorante natural no calórico . Rev chil Nuti.2012;39(4):203-6.

6 Brandle JE, Richman A, Swanson AK, Chapman BP. Leaf ESTs from Stevia rebaudiana: a resource for gene discovery in diterpene synthesis. Plant Mol Biol 2002; 50(4-5):613622.

7 Hidalgo E. Nuevos métodos en la prevención de caries dental: Xilitol, probióticos y otros. [Título de Cirujano Dentista]Lima:Facultad de Estomatología ,Universidad Peruana Cayetano Heredia;2011

8 Laprade, N., Hernández, R., Arias, M.L. Valverde, A. Eficacia del Gluconato de Clorhexidina. Odontología. Vital.Rev Odontologia Vital.2014;1(20):19-26.

9 Velasquez C.et.al. Effect of xylitol chewing gum on dental plaque, saliva flow and saliva buffer.Int.J.Odontoestomat.2013;7(1):133-7.

10 Bohador A et al. Effect of xylitol on cariogenic and beneficial oral streptococci: a randomized, double-blind crossover trial. Iran. J. Microbiol.2012;4(2):75-81.

11 Gholam R et.al. Comparative inhibitory effect of xylitol and erythritol on the growth and biofilm formation of oral Streptococci. African Journal of Microbiology Research.2012;6(20):4404-8.

12 Vitery G et.al. Actividad inhibitoria de la Stevia Rebaudianatans. Revista Nacional de Odontología.2010;6(10):57-64.

13 Perez $\mathrm{C}$ et.al. Use of chewing gum containing $15 \%$ of xyltol and reduction in Streptococci mutans salivary levels.Braz Oral Res. 2010; 24(2):142-6142.

14 Manish B, et al. In vitro antimicrobial activity of Stevia Rebaudiana Bertoni leaves. Tropical Journal of Pharmaceutica Research.2006;5(1):557-560.

15 Batellino L, Lissera R, De Yankilevich, Francia C.Efecto del xilitol sobre la formación de película adquirida bajo condiciones in vitro. (Spanish).Medicina Oral.2003;5(1):13-21.

16 Lopez $\mathrm{N}$ et.al. Efeito de soluções fluoretadas contendo xilitol e sorbitol no número de estreptococos do grupo mutans na saliva de seres humanos. Rev Panam Salud Publica/Pan Am.2001;9(1):30-34

Recibido: 20 de Abril de 2016

Aceptado: 15 de Mayo de 2016 